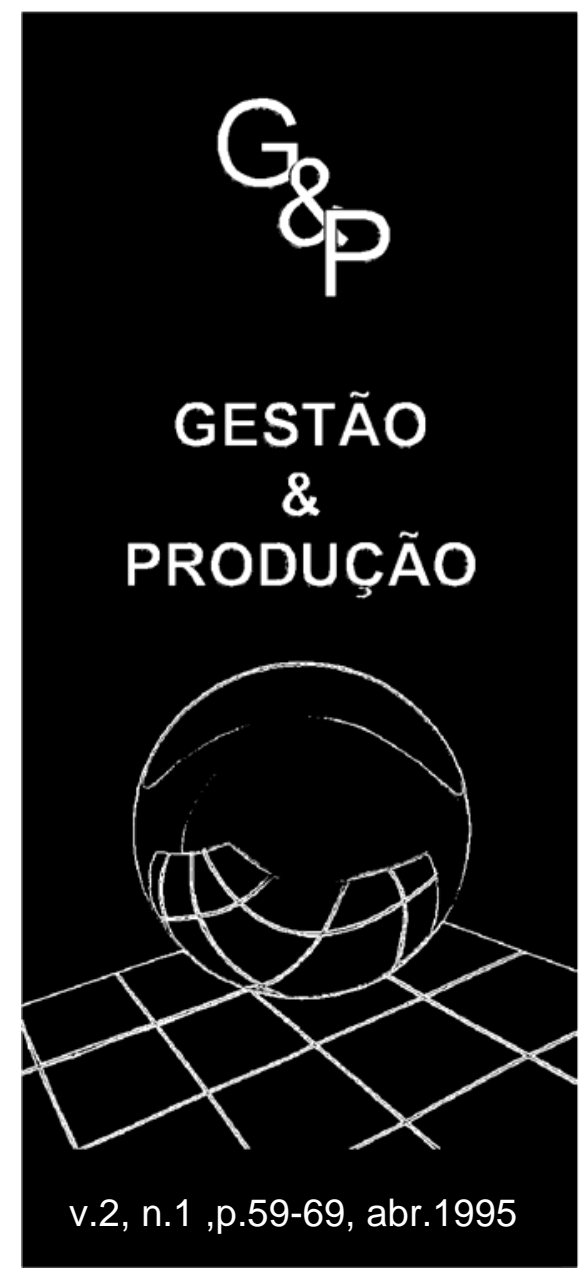

\title{
IMPLANTAÇÃO DE KANBAN COMO TÉCNICA AUXILIAR \\ DO PLANEJAMENTO E CONTROLE DA PRODUÇÃO: UM ESTUDO DE CASO EM FÁBRICA DE MÉDIO PORTE
}

Ethel Cristina Chiari da Silva

Doutoranda do Departamento de Engenharia Mecânica da Escola de Engenharia de São Carlos - USP

José Benedito Sacomano

Prof. Dr. do Depto. de Engenharia Mecânica da Escola de Engenharia de São Carlos - USP fone: 0162-72.6222

\section{Resumo}

O presente artigo relata a experiência da implantação do sistema Kanban em uma célulapiloto, realizada em uma fábrica de médio porte do setor metal mecânico em São Carlos SP. A intenção da implantação do sistema kanban surgiu como expectativa de auxílio ao Planejamento e Controle da Produção, a fim de buscar padrões tecnológicos de gestão mais adequados à realidade mundial. Para implantação do sistema Kanban criou-se um ambiente Just-in-Time na célula piloto a fim de gerar um sistema consistente e também um modelo de aprendizado para a fábrica. Trabalhou-se com operários de baixa escolaridade e elaborouse todo o material didático utilizado nas atividades de treinamento. Após um ano e meio (1130 horas) de trabalho na fábrica, pôde-se chegar a resultados altamente satisfatórios, tanto qualitativos quanto quantitativos.

\section{Palavras-chave: Planejamento, Controle, Kanban, Treinamento, Célula.}

\section{Introdução}

Destaca-se inicialmente o caráter exploratório desta pesquisa, mais especificamente, um caráter de intervenção in loco nas atividades de Planejamento e Controle da Produção (PCP) desenvolvidas no chãode-fábrica, para possibilitar um confronto entre teoria e prática.
A convivência com a realidade e o cotidiano de uma fábrica, com a possibilidade de interferência nessa realidade, é uma experiência rica e extremamente difícil. Difícil porque expõe dois universos, aparentemente antagônicos, em confronto dire-to, ou seja, uma atividade intelectual de 
pes-quisa versus a atividade complexa de se produzir bens ou serviços.

Trabalhos realizados por FLEURY (1978), MACHELINE (1985), RESENDE (1989), SACOMANO (1990), MARTINS (1993), vem encurtando a distância entre a Universidade e a empresa.

Com relação à escolha das atividades de PCP, é importante mencionar que elas podem ser consideradas como o centro nervoso do sistema de manufatura, com funções de coordenação e ponto de integração. Para ZACCARELLI (1982), as atividades de PCP apresentam acentuado caráter coordenador do processo produtivo e grande interação com as demais áreas do sistema de manufatura. LINK (1978) afirma que o PCP apresenta caráter de coordenação de funções e ponto de integração de procedimentos administrativos.

A investigação nas atividades de PCP pode fornecer claros indícios de como um sistema de manufatura está introduzindo novas formas de organização industrial.

É importante destacar que uma administração da produção deficiente não consegue atender as novas dimensões de competição apontadas por BUFFA \& SARIN (1987) como sendo: custo, qualidade, prazo de entrega, flexibilidade e serviço ao consumidor.

Portanto, o PCP converte-se ao mesmo tempo em "janela de observação" de toda a fábrica assim como a "porta de entrada" para o sistema produtivo. No presente estudo foi acrescentado um sistema Kanban numa célula piloto, como tentativa de supe-ração da fase do PCP convencional para atividades mais próximas ao novo paradig-ma produtivo mundial.

A escolha de implantação do sistema Kanban se deu após um período de convivência durante o qual, de início, se teve contato com os procedimentos rotineiros do PCP, seus problemas e propostas de melhoria, sentindo assim o ambiente da organização, para, então, propor um projeto que tivesse grande aceitação no âmbito da empresa e condições que tornassem factível sua implementação.

Notou-se nesta fase o interesse por parte da empresa nas novas técnicas de gestão da produção, principalmente as aplicadas no Japão. Decidiu-se explorar mais esta questão. Foram realizadas 22 entrevistas com pessoas dos diferentes setores da produção. Com estas entrevistas foi possível registrar os principais problemas da produção e também algumas sugestões.

Em seguida, estudou-se cada setor da produção, para verificação dos processos e do fluxo de materiais.

Portanto, na convivência com os procedimentos das rotinas do PCP, por meio das entrevistas e do contato com os setores, pôde-se ter uma boa visão do sistema de manufatura. $\mathrm{O}$ interesse da pesquisa estava centrado nas novas técnicas de gestão da produção; portanto, achou-se bastante oportuno o interesse da empresa no sistema Kanban e decidiu-se propor o desenvolvimento de um setor piloto. O treinamento da mão-de-obra viria constituir um ponto forte do presente trabalho como será visto.

\section{A Fase de Desenvolvimento}

Quando se deseja implantar o sistema Kanban, deve-se seguir alguns mecanismos de implantação. Com base em MONDEN (1984), SCHONBERGER (1987) e MOURA (1989) definiram-se os seguintes passos:
Preparar o grupo para os conceitos da filosofia Just-in-Time.

Escolher um setor piloto para permitir o aprendizado da técnica.

Determinar a demanda anterior, peça a peça. 
Definir as quantidades por contenedor (container).

Estudar o lead time de reposição de cada peça.

Definir o tipo de sistema Kanban (duplo cartão, cartão único) e os procedimentos.

Definir o número e os tipos de cartões para cada peça.

Estudar o lay out do setor.

Criar painéis porta-Kanbans.

Todos esses passos estão detalhados em SILVA (1994). Cabe aqui uma observação com relação à escolha do setor piloto.

Um bom candidato a setor piloto, conforme MOURA (1989), é aquele que apresenta um número pequeno de itens individuais, com programas de produção razoavelmente estáveis, e com poucas restrições de produção (capacidade, tamanho do lote, etc).

Como foi comentado, no início do traba-lho levantou-se o fluxo de materiais no chão-de-fábrica, isto foi feito pelo contato com os encarregados das células, em que se ve-rificaram todos os processos e fluxos de materiais, o que possibilitou uma boa visão do chão-de-fábrica e um
Com esta "caminhada" pelo chão-defábrica e analisando-se o fluxo de materiais, o setor Cabos Clusters revelouse um bom candidato à célula piloto. Decidiu-se então explorar mais detalhadamente este setor e foi constatado o seguinte:

Produz pequeno número de itens individuais

Poucas interações com outros produtos

Possui espaço para o supermercado

Está passando por implantação de programas de qualidade e existe por parte do encarregado da célula um grande interesse em conhecer o sistema Kanban e aplicá-lo, além do desejo de contínuas melhorias no setor. É o segundo produto da empresa em termos de faturamento.

Fizeram-se também estudos com relação à capabilidade dos processos (capacidade do processo manter os padrões estabele-cidos), manutenção, refugos, etc.

Dessa maneira, o setor Cabos Clusters foi escolhido como setor piloto para elaboração do sistema Kanban.

Os produtos da família cluster são: cabeçotes com chicotes de fios (três fios). 
ração. A família é composta por sete tipos de cabos clusters, dos quais quatro podem ser vistos na foto 1.

\section{Foto 1: Cabos Clusters}

Com relação ao tipo de sistema Kanban, único ou duplo cartão, uma apresentação detalhada pode ser vista com detalhes em SCHONBERGER (1983; 1987) e MOURA (1989).

Na figura 1 pode-se ver o diagrama de funcionamento do sistema Kanban (de cartão único) proposto. Como observação menciona-se que o suprimento de materiais é efetuado, de acôrdo com a programação, no próprio centro de trabalho. $\mathrm{O}$ posto de coleta indica a programação para o próximo período, ante a retirada de produtos prontos pelo cliente. O cartão retorna ao painel, reiniciando o ciclo do sistema Kanban de cartão único.

Figura 1: Diagrama de Funcionamento do Sistema Kanban Proposto.

\section{A Implantação}

\subsection{A Preparação da Mão-de-Obra}

Decidida a implantação, iniciou-se a ela-boração e execução de um curso de treina-mento, o qual foi dividido em três módulos. O curso foi dimensionado para duração total de aproximadamente seis 
horas, sendo duas horas para cada módulo. Este curso foi ministrado a várias turmas.

O módulo 1 refere-se a uma simulação em que se compara o sistema de produção convencional e o sistema Just-in-Time (JIT); para tanto, utiliza-se a simulação de fabri-cação de canetas azuis e vermelhas, que devem ser montadas conforme a lógica dos dois sistemas.

A aplicação do módulo 1 transmite, de forma clara, a lógica dos dois sistemas e desperta o interesse das pessoas para a realização de mudanças em seus respectivos setores, a fim de obter deles um melhor desempenho.

O módulo 2 consta de uma apostila, a qual foi elaborada para treinamento das pessoas do chão-de-fábrica. Na elaboração desta apostila teve-se a preocupação de colocar os conceitos com linguagem simples e arte final apropriada.

O objetivo do módulo 2 é transmitir, mais detalhadamente, o que é a produção Just-in-Time, seus pré-requisitos, alguns conceitos e o funcionamento do sistema Kanban como uma ferramenta da produção JIT.

É importante, no módulo 2, mostrar como as pessoas podem participar a fim de se atingir a produção JIT. Isto é feito pelo conhecimento das ferramentas ou prérequisitos, fase em que as pessoas discutem o que pode ser feito com a colaboração de cada um. Este módulo é antes de tudo um estímulo para discussões.

Quanto ao módulo 3, ele é um treinamento específico para mostrar como vai funcionar o sistema Kanban da empresa; apresentar os cartões e os procedimentos adotados. Neste módulo, os operários praticaram os novos procedimentos mediante simulação da situação real e tomaram as decisões interpretando o painel. Este módu-lo é bastante didático, transmitindo de for-ma clara o sistema adotado pela empresa.

Após os três módulos ou etapas, pôdese concluir que houve uma absorção dos conceitos por parte dos operários, melhorando portanto sua qualificação.

Em turmas que já haviam assistido a outros cursos, como por exemplo lay-out, o resultado foi surpreendente, o que mostra a necessidade de reunião de todas as áreas, a fim de elaborar um programa de treinamento integrado, de modo que haja um melhor aproveitamento dos cursos ministrados na fábrica.

Cabe observar, aqui, que foram colocadas placas no caminho para a célula piloto, contendo conceitos e regras do sistema Kanban. Isso foi feito com o objetivo de fazer com que as informações chegassem o mais próximo possível das pessoas do chão-de-fábrica, de forma que elas pudes-sem ler e se auto instruir, o que ajudou a estimular a curiosidade dos outros setores.

Assim sendo, montou-se um kit de treinamento - composto dos módulos 1, 2, 3 para o programa Just-in-Time.

Com relação à importância da preparação da mão-de-obra, FERRO (1990: 1992) declara que "apesar de todas as inovações e revoluções tecnológicas trazidas pelo Siste-ma de Produção Toyota, sem dúvida sua força fundamental encontra-se na qualidade e motivação do pessoal. O aproveitamento da potencialidade humana em todos os níveis é um dos grandes méritos do siste-ma." Portanto, uma força de trabalho motivada e comprometida é de importância crucial.

Entretanto, é impossivel comprometer ou motivar o trabalhador quando este não sabe por que nem para que está realizando determinada atividade.

Neste sentido houve uma experiência bastante valiosa, pois foi possível ensinar aos trabalhadores os meandros da nova técnica a ser implementada, com material didático apropriado, criado para tal finalidade e, principalmente, utilizando a célula piloto como um laboratório didático para que os trabalhadores pudessem ter entendi- 
mento dos conceitos que vigoram na biblio-grafia geral sobre kanban.

\subsection{Mudanças Efetuadas no Setor}

Para implantação do sistema Kanban, foram efetuadas algumas mudanças no setor, das quais as principais foram: um pro- grama de organização e limpeza, e a organização do supermercado.

As fotos 2 e 3 deixam claro o que foi realizado.

Foto 2: Vista do local antes da organização do supermercado 


\section{Foto 3: Vista do local do supermercado pronto para funcionamento}

\section{Considerações Sobre a Empresa e os Resultados}

Antes de nos reportarmos aos resultados é importantíssimo fazer breves considerações sobre a empresa em que se realizou a pesquisa.

A empresa mostrou-se, desde o início, extremamente aberta à pesquisa e às mudanças que fossem passíveis de implantação. Isto não é comum ou corriqueiro na empresa brasileira, que ainda resiste a uma integração mais profícua com a Universidade. Neste sentido a empresa pesquisada mostra grande lucidez, servindo de laboratório para a pesquisa desenvolvida. Mesmo assim, ocorreram, no chão de fábrica, rejeições naturais à implantação de uma nova sistemática de trabalho. Essa situação perdurou por volta de dois meses. O que que- gerên-cia de produção nestas industrias é tão importante como em qualquer outra, ante as grandes perdas e desperdícios quando as atividades de planejamento e controle eram mal executadas ou negligenciadas.

Dada esta preocupação, buscou-se manter na empresa um movimento, que já fora iniciado havia algum tempo, na busca de padrões tecnológicos de gestão mais adequados à realidade mundial. Procurou-se estabelecer um critério de implantação com acompanhamento passo a passo, buscando melhorias contínuas no processo produtivo, sem perturbar profundamente 0 andamento das atividades do chão-defábrica. Pode-se mencionar aqui, como brou essa barreira foi a assimilação da técnica por parte dos operários.

Convém ainda lembrar que, como menciona SACOMANO (1983) pesquisando o PCP na pequena e média indústria, a uma dificuldade ini-cial, a falta de materiais no Centro de Trabalho (figura 1), devido ao aumento da velocidade (diminuição do ciclo de fabri-cação) da célula, o que não pôde ser acom-panhado, 
inicialmente, pelo fornecedor desses materiais.

Com relação ao sistema Kanban, foco principal da pesquisa, é importante destacar uma observação feita por Taiichi Ohno em uma entrevista que se encontra em MOURA (1989): "o Kanban deve ter início sempre dentro de uma área da empresa, passar paulatinamente para outra, ter suas falhas corrigidas e ser consolidado inter-namente, para só depois ser passado ao fornecedor. É um trabalho contínuo e per-manente de aperfeiçoamento." E ainda, "começar o Kanban de fora para dentro da empresa é o maior erro que se pode cometer."

Fica, portanto, consignada a importância de se iniciar por um setor piloto, para permitir o aprendizado da técnica e, só depois, expandir o sistema. Para essa ex-pansão é necessário criar uma mentalidade de cliente-fornecedor na organização toda.

É de fundamental importância que depois da implantação do sistema, reserve-se um tempo para medir seu desempenho e aumentar seus benefícios.

Observa-se ainda que MONDEN (1984) alerta para o cuidado de não se confundir simples com simplista, pois apesar da teoria do sistema Kanban ser bastante simples, sua implementação é de extrema complexi-dade.

A falta de entendimento da filosofia JIT, pode levar a um fraco aproveitamento da técnica, ou, pior, ao fracasso e posterior abandono, provocando geralmente uma "repulsa" pela técnica, caracterizada pelo fracasso anterior.

A implantação apresentou ótimos resultados. Os resultados quanificáveis foram obtidos a partir de dados coletados da seguinte maneira:

- antes da implantação os dados vieram da comparação entre: os registros de vários anos da programação de recebimentos dos clientes, os dados dos recebimentos efetivados e os registros das entradas de materiais;

- após a implantação os dados foram coletados diretamente no supermercado.

Os resultados podem ser resumidos da seguinte maneira:

Redução de 50\% de estoque em processo medido no período de novembro de 1993 a abril de 1994 (6 meses).

Eliminação completa de todos os atrasos no mesmo período. Antes da implantação tinha-se um atraso médio de 72.000 peças/mês.

Redução de $70 \%$ no estoque de produtos acabados.

Aumento da organização e limpeza do setor.

Alto grau de aprendizado da mão-deobra.

Localização de apenas uma peça defei-tuosa em um total de 1.800 .000 (um milhão e oitocentas mil) entregues no período de novembro de 1993 a abril de 1994 (dado fornecido pelo controle de qualidade do cliente).

\section{Considerações Acerca das Novas Técnicas de Gestão da Produção no Contexto Brasileiro}

Nos últimos anos a economia brasileira tem-se caracterizado por uma forte instabilidade político-economica, recessão e altas taxas inflacionárias.

No início da década de 90, houve a abertura da economia brasileira e os produtos estrangeiros começaram a competir intensamente com os produtos nacionais. Esses produtos, geralmente advindos de países onde o novo paradigma já está consolidado, apresentam maior qualidade, design moderno e maior variedade, além de serem bastante competitivos, no tocante a preços, com os similares nacionais. 
Este fato veio colocar ao alcance dos consumidores uma maior variedade de produtos, de alta qualidade e a preços acessíveis, refletindo assim uma tendência mundial.

Dentro desta nova conjuntura, a empresa brasileira vê-se diante da necessidade de se adequar a essa tendência, adotando técnicas compatíveis, guardadas as limitações existentes no país, com o novo paradigma produtivo mundial. A produção Just-inTime apresenta enormes vantagens nesse sentido, trazendo ao sistema de manufatura maior flexibilidade para atender à variedade da demanda, além da preocupação com o fator qualidade e a possibilidade de preços competitivos pela redução dos custos de produção.

Como não há a menor chance de importação pura e simples tanto das técnicas quanto da filosofia que as gerou, haverá então necessidade de fortes ajustes na implantação de tais técnicas (SACOMANO ,1990; MARTINS, 1993).

Em meados da década de 80, o êxito japonês começou a tornar-se mais evidente, o que aguçou, no âmbito da empresa brasi-leira, a disposição de imitar os métodos e procedimentos tidos como responsáveis por aquele êxito, conforme se pode observar pelo grande número de publicações divul-gadas, por exemplo, pelo IMAM (Instituto de Movimentação e Armazanagem de Ma-teriais). Conforme FERRO (1992) muitas vezes, enxergou-se apenas a ponta de um iceberg, identificando-se o sistema apenas por meio de uma de suas técnicas. É o caso dos Círculos de Controle de Qualidade (CCQ), que provocaram grande febre na indústria nacional e hoje estão praticamente abandonados.

Com relação à transferência das técnicas, RESENDE (1989) afirma que a maioria da industria latino-americana se estabeleceu tendo como base a transferência de técnicas provenientes de países mais desen-volvidos, sem que se realizasse nenhum tipo de pesquisa tecnológica, necessária pa-ra adaptá-las às condições locais. $\mathrm{O}$ autor citado pesquisou um número significativo de empresas para chegar a esta conclusão, e menciona, ainda, que todas as mudanças a fim de reverter o quadro relatado, apare-ceram na segunda metade dos anos 80. Entretanto, este movimento de mudança se dá sem uma diretriz bem definida, e dentro de um ambiente de incertezas tão preocu-pante que exige cautela, tanto de quem analisa quanto de quem implementa as novas técnicas.

A indústria brasileira não é competitiva internacionalmente e tem continuado a perder espaço na concorrência global. FLEURY (1983) observa que, entre os fatores que têm dificultado as vendas dos manufaturados brasileiros no exterior são citados, freqüentemente, o preço, a qualidade e a incapacidade de cumprir prazos de entrega. Hoje, no mundo, o emprego de novas técnicas de gestão da produção a fim de adequar os sistemas de manufatura ao novo paradigma produtivo mundial é uma questão de sobrevivência ante a intensa competição global.

FERRO (1992) afirma que a indústria no Brasil pode ter um dos maiores crescimentos do mundo, nesta virada de século, caso consiga adotar rapidamente esse novo padrão de produção.

Com relação à adoção do novo padrão mundial de produção destaca-se que é possível a difusão ampla no Brasil das novas técnicas de fabricação oriundas do Japão, pois, como em qualquer processo de inovação, os pioneiros, países ou empresas, obtêm vantagens com seu uso, mas gradualmente ocorre o aprendizado quando as novas técnicas são incorporadas por novos usuários, tornando-se disponíveis para os demais sistemas de manufatura e se adequando às mais diferentes condições.

O presente trabalho confirma na prática a última afirmação, porém ressalta de forma veemente que a adaptação das 
técnicas deve ser cuidadosamente estudada, não se tratando de um processo simples.

Esta adaptação e a conseqüente transição para um patamar superior em termos de gestão da produção poderão acontecer se requisitos como o aprendizado das novas técnicas, a estabilização da demanda e a escolarização da mão-de-obra forem obser-vados.

Com relação à estabilização da demanda, nota-se que as novas formas de organização da produção foram desenvolvidas nos países do primeiro mundo, onde a economia e a demanda são estáveis.

Quanto à escolarização da mão-de-obra, FERRO (1992) cita que os trabalhadores brasileiros têm muito pouco treinamento comparativamente aos de outros países, o que é agravado pela baixa escolarização e pelo baixo nível do ensino proporcionado pelo sistema escolar. Além disso, a ausência de esquemas de aprendizado constante, no próprio trabalho, por meio de superviso-res cuja tarefa seria ensinar e guiar, e não vigiar e controlar, prejudica ainda mais a capacitação dos trabalhadores no Brasil. Mesmo mostrando disposição para colabo-rar e aprender, existe falta de preparo téc-nico adequado para poder influir mais dire-tamente na resolução de problemas. Não se trata apenas de mais treinamento técnico, mas efetivamente de melhor educação.

O Brasil é um dos países de maior desnível social, ou grau de desigualdade nas relações sociais, o que se reflete nas organizações industriais. O maior fracasso na difusão do novo modo de produção oriundo do Japão verifica-se, segundo FERRO (1992), nos sistemas de trabalho e nas polí- ticas de Recursos Humanos que, de forma geral, reproduzem uma ideologia brasileira, responsável pela má distribuição de renda.

Existem também, conforme o autor citado, alguns pontos positivos nas práticas gerenciais no Brasil, com a existência de esquemas de rotação de tarefas, mais freqüentes do que em quase todos os países, apenas inferiores aos índices japoneses e coreanos, apontando assim uma grande flexibilidade e capacidade de adaptação da mão-de-obra brasileira, não obstante sua pouca preparação técnica.

É necessário lembrar que o caminho da transição é longo e com muitos obstáculos. Ressalta-se o fato de que serão necessários muitos anos para a implementação completa dos novos elementos que compõem as técnicas de gestão e, que talvez o mais di-fícil ainda seja a mudança da postura vigen-te no âmbito das empresas. É necessário, portanto, pensar-se a longo prazo, sem perder de vista que a indústria precisa caminhar hoje e, assim sendo, soluções rápidas e condizentes com a globalização da economia precisam ser encontradas, o que torna imperiosa a necessidade da implantação e ajuste das novas técnicas, de maneira lúcida e sem falsas esperanças.

Pela experiência relatada, a qual focaliza um única célula, pode-se antever uma grande possibilidade de melhorias sistemá-ticas nos processos produtivos, por meio da escolarização da fábrica como um todo e da introdução de técnicas mais modernas de gestão, para que o país possa, a médio prazo, produzir riquezas e distribuí-las à sociedade que as gera.

\section{Referências Bibliográficas}

BUFFA, E.,SARIN, R.K.: Modern production/operations management. (8 ed., 834p.). John Wiley \& Sons, 1987.
FERRO, J.R.: "Aprendendo com o "Ohnoísmo" (produção flexível em massa): lições para o Brasil". Revista 
de Administração de Empresas, v.30, n.3, p.57-68, Jul/Set 1990.

FERRO, J.R.: "A produção enxuta no Brasil". In: WOMACK, J.P.; JONES, D.T.; ROOS, D.: A máquina que mudou o mundo. (3 ed.; p.311-337). Editora Campus, Rio de Janeiro, 1992.

FLEURY, A.C.: Organização do trabalho industrial: um confronto entre teoria e realidade. Tese de Doutorado (172p.), Escola Politécnica/USP, S.Paulo,1978.

FLEURY, P.F.: "Planejamento e controle da produção em empresas exportadoras e não-exportadoras: um estudo comparativo". Revista de Administração, v.18, n.3, p.18-26, Out/Dez 1983.

LINK, H.: Programação e controle da produção. Edgard Blucher, São Paulo, 1978.

MACHELINE, C.: "Planejamento e controle da produção na indústria nacional de bens de equipamentos". Revista de Administração de Empresas, v.25, n.2, p.5-28, 1985.

MARTINS, R.: Flexibilidade e integração no novo paradigma produtivo mundial: estudos de casos. Dissertação de Mestrado (143p.), EESC/USP, São Carlos, 1993.

MONDEN, Y.: Sistema Toyota $d a$ Produção. (141p.). IMAM, 1984.

MOURA, R.A.: Kanban - a simplicidade do controle da produção. (355p.). IMAM, 1989.

RESENDE, M.O.: Planejamento e controle da produção: teoria e prática da indústria mecânica no Brasil. Tese de Doutorado, EESC/USP, São Carlos, 1989.

SACOMANO, J.B.: O planejamento $e$ controle da produção na pequena $e$ média indústria de São Carlos. Dissertação de Mestrado (148p.), EESC/ USP, São Carlos, 1983.

SACOMANO, J.B.: Uma análise da estrutura funcional do planejamento $e$ controle da produção e suas técnicas auxiliares. Tese de Doutorado (378p.), EESC/USP, São Carlos, 1990.

SCHONBERGER, R.J.: "Applications of single-card and dual-card Kanban". Interfaces, v.13, n.4, p.56-67, August 1983.

SCHONBERGER, R.J.: Técnicas industriais japonesas: nove lições ocultas sobre a simplicidade. (2 ed., 309p.). Pioneira, São Paulo, 1987.

SILVA, E.C.C.: Kanban em célula piloto como técnica auxiliar do planejamento e controle da produção: um estudo de caso em fábrica de médio porte. Dissetação de Mestrado (124p.), EESC/USP, São Carlos, 1994.

ZACCARELLI, S.B.: Programação $e$ controle da produção. (6 ed., 293p.). Pioneira, São Paulo, 1982. 
The present article reports the experience of the Kanban system implantation on a pilot cell at a medium-size factory in the mechanical metal sector in São Carlos - SP. The reason for implanting the Kanban system arose in the hope of aiding Production Planning and Control in order to seek technological standards of administration more adequade to the world reality. For the kanban system implantation a Just-in-Time environment has been created at the pilot cell to generate a consistent system as well as a learning model for the factory. The work has been done with employees who have had low schooling and all didactical material used has been elaborated using training activities. After one and a half years' (1130 hours) work at the factory, highly satisfactory results - both qualitative and quantitative - have been attained.

Key-words: Planning, Control, Kanban, Training, Cell. 